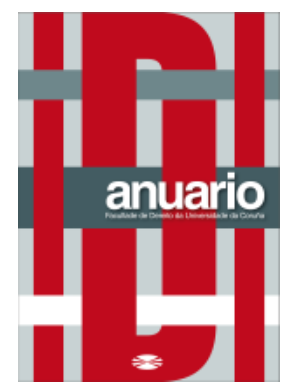

Anuario da Facultade de Dereito da Universidade da Coruña

Vol. 21 (2017), pp. 229-258

ISSNe: 2530-6324 || ISSN: 1138-039X

DOI: https://doi.org/10.17979/afdudc.2017.21.0.3279

\title{
LOS PARTIDOS POLÍTICOS EN MÉXICO. EL PARADIGMA DE LA RENDICIÓN DE CUENTAS EN EL MARCO DE LAS REFORMAS EN MATERIA DE TRANSPARENCIA Y ACCESO A LA INFORMACIÓN
}

\author{
ENOC FRANCISCO MORÁN TORRES \\ Doctor en Derecho. Profesor de la Facultad \\ de Derecho de la Universidad de Colima (México) \\ Marco Antonio VALENCIA VILlatoro \\ Licenciado en Derecho. \\ Universidad de Colima (México)
}

\begin{abstract}
Resumo: El presente artículo se avoca al estudio de la reforma constitucional en materia política-electoral del año 2014 que realizó el Estado Mexicano, particularmente las nuevas instituciones y disposiciones normativas relativas a la fiscalización de los Partidos Políticos y a la transparencia y acceso a la información en el ámbito electoral, su interacción con el ámbito político y social de nuestro país y el papel que desempeñarán los organismos constitucionales autónomos en la tarea de vigilar que las referidas entidades de interés público cumplan con las obligaciones que legal y constitucionalmente tengan encomendadas sobre el particular en aras de transitar al Estado Constitucional Democrático de Derecho. Estudio que se fortalece a partir de la perspectiva que aporta el derecho comparado en algunos países de Iberoamérica.
\end{abstract}

Palabras clave: partidos políticos; transparencia; fiscalización; Estado Constitucional Democrático de Derecho.

Abstract: This paper is a research about the constitutional reform made in the year 2014 by the Mexican state on political-electoral affairs, particularly the new institutions and legal dispositions relative to the auditing of the political parties and the transparency and access of information in the electoral field, the interaction with the political and social fields in Mexico and the role assumed by the constitutional 
autonomous organisms in the task of monitoring the aforementioned political parties and whether or not they comply with their constitutional and legal obligations in the topics already enlisted, so the transition to a Constitutionally Democratic State of Law is possible. The consolidation of this research is achieved via the perspective of comparative law in some Iberoamerica countries.

Keywords: political parties; transparency; auditing; Constitutionally Democratic State of Law.

SUMARIO: I. INTRODUCCIÓN. II. MARCO TEÓRICO. III. LA REGULACIÓN DE LOS PARTIDOS POLÍTICOS EN MÉXICO. IV. LA REFORMA MEXICANA EN MATERIA POLÍTICA-ELECTORAL 2014. V. LA FISCALIZACIÓN Y TRANSPARENCIA DE LOS PARTIDOS POLÍTICOS EN MÉXICO. VI. ANÁLISIS DE LA TRANSPARENCIA EN EL DERECHO COMPARADO. VII. CONCLUSIONES. VIII. FUENTES DE CONSULTA.

\section{INTRODUCCIÓN}

El Estado Mexicano durante los años 2013 y 2014 ha sufrido una gran variedad de cambios en diversas instituciones y disposiciones normativas, resaltando en el presente trabajo dos materias de trascendental importancia: la materia política-electoral y la de transparencia y acceso a la información.

Por lo que la presente contribución académica abordará el tema de la transparencia, acceso a la información y fiscalización en los Partidos Políticos, a propósito de las reformas citadas con antelación, así como el estudio de las nuevas disposiciones normativas que regulan las materias en comento, las cuales se encuentran previstas en la legislación secundaria en materia política-electoral denominada Ley General de Partidos Políticos (LGPP), visión que se ve enriquecida con el estudio de derecho comparado en algunos países de Iberoamérica.

En esa línea argumentativa se abordará el estudio de los nuevos organismos encargados de realizar las labores en materia de transparencia, acceso a la información y fiscalización de los Partidos Políticos, verbigracia, el Nuevo Instituto Nacional Electoral (INE) a través de la Unidad Técnica y la Comisión de Fiscalización; Los órganos de los Partidos Políticos encargados de administración de su patrimonio, recursos financieros, de la presentación de los informes de ingresos y egresos trimestrales y anuales, de precampaña y campaña; así como el encargado de cumplir con las obligaciones de transparencia y acceso a la información que la Constitución y las leyes de la materia imponen a los Partidos Políticos; el organismo autónomo denominado Instituto 
Nacional de Transparencia, Acceso a la Información y Protección de Datos Personales (INAI); y la Secretaría de Hacienda y Crédito Público (SHCP).

Todo lo anterior se realiza con la finalidad de resaltar las labores realizadas por las nuevas figuras jurídicas implementadas por el Estado Mexicano en materia de Transparencia y acceso a la información política-electoral en aras de consolidarse en un Estado Constitucional Democrático de Derecho.

\section{MARCO TEÓRICO}

El Estado de Derecho lo podemos definir como la sujeción total del poder público al Derecho, en ese sentido Platón, al distinguir el buen gobierno del mal gobierno señalaba:

Los gobernantes deben ser los servidores de las leyes, en una ciudad donde la ley está sujeta y no tiene fuerzas, veo muy cercana su ruina; pero allí donde a ley reina sobre los gobernantes y donde los gobernantes se hacen a sí mismos esclavos de la ley, veo nacer allí la salvación y, con ella todos los bienes que los dioses otorgan a las ciudades ${ }^{1}$

En esa tesitura, Aristóteles se realizaba la pregunta siguiente: ¿es más conveniente ser gobernado por los mejores hombres o por las mejores leyes?, pregunta a la cual respondía de la siguiente manera:

Es preferible que gobierne la ley que uno cualquiera de los ciudadanos, y según este mismo principio, aun cuando sea mejor que gobiernen determinados hombres, ellos deben ser designados como custodios de las leyes y como subordinados a ellas. La razón de esta afirmación es porque la ley está libre de pasiones, las cuales pueden torcer el gobierno aun de los hombres mejores; en cambio, las leyes son sabiduría sin deseo. ${ }^{2}$

En esa línea argumentativa, Bobbio establecía la doctrina del gobierno de las leyes, que se fundamentaba en el principio de la subordinación del rey a la ley, doctrina que es el fundamento del Estado de derecho entendido, en su acepción más restringida como el Estado cuyos poderes son ejercidos en el ámbito de las leyes preestablecidas. ${ }^{3}$

En ese sentido, a lo largo de la historia las realidades sociales, políticas, económicas y culturales de los Estados, les han permitido evolucionar hacía nuevas realidades, mismas que han impactado en la evolución del derecho y en la concepción de éste, y por ende, al Estado de Derecho, identificando los grandes teóricos tres evoluciones del mismo:

1. El Estado Legalista de Derecho

2. El Estado Constitucional de Derecho

3. El Estado Democrático Constitucional de Derecho

\footnotetext{
1 Ruiz Rodriguez, Virgilio. Estado de Derecho y Soberania, http://www.juridicas.unam.mx/publica/librev/rev/jurid/cont/34/pr/pr16.pdf Fecha de acceso: 20 de agosto de 2015.

2 Íbidem.

${ }^{3}$ Íbidem.
} 
Así las cosas, el Estado Legalista consistía en cualquier estructura formal donde se respetaran las leyes, carentes de contenido y adaptables a cualquier ideología, sin tomar en cuenta las exigencias materiales y espirituales del ser humano, partiendo de su dignidad como persona. ${ }^{4}$

Luigi Ferrajoli contemplaba al Estado Legislativo de Derecho con la afirmación del principio de legalidad como criterio exclusivo de identificación del Derecho válido, con independencia de su valoración como justo; una norma jurídica es válida no por ser justa, sino exclusivamente por haber sido puesta por una autoridad dotada de competencia normativa. ${ }^{5}$

Dicha etapa del Estado de Derecho se vio superada por las realidades sociales, culturales, políticas y económicas que aparecieron con el estallido de las guerras mundiales, en especial por la Segunda Guerra Mundial, en la cuál bajo el amparo del Estado Legal de Derecho se cometieron genocidios y diversos crímenes, los cuales al estar amparados en un cuerpo normativo, por ejemplo la ley alemana, eran considerados legales y no crímenes, al estar permitidos por la ley, independientemente de si la misma fuera justa o injusta.

En ese sentido, el Estado Legalista de Derecho evolucionó al Estado Constitucional de Derecho, el cual según Manuel Atienza:

Es el Estado en el que la Constitución (que puede no serlo en sentido formal: puede no haber un texto constitucional) contiene: a) un principio dinámico del sistema jurídico político, o sea la distribución formal del poder entre los diversos órganos estatales; b) ciertos derechos fundamentales que limitan o condicionan (también en cuanto contenido) la producción, la interpretación y la aplicación del derecho, c) mecanismos de control de la constitucionalidad de las leyes. Como consecuencia, el poder del legislador (y el de cualquier órgano estatal) es un poder limitado y que tiene que justificarse en forma mucho más exigente. No basta con la referencia a la autoridad (al órgano competente) y a ciertos procedimientos, si no que se requiere también (siempre) un control en cuanto al contenido. ${ }^{6}$

En efecto, Manuel Atienza señala que este Estado implica que las autoridades que detentan el poder deben realizar una mayor argumentación al momento de emitir sus determinaciones, esto es deben fundamentar y motivar sus actuaciones, puesto que el Estado Constitucional de Derecho implica "el sometimiento completo del poder al derecho, a la razón: la fuerza de la razón, frente a la razón de la fuerza".?

Prosiguiendo con la evolución del Estado de Derecho, se llega al Estado Constitucional Democrático de Derecho, el cual en palabras de Häberle se caracteriza por la dignidad humana como premisa antropológica-cultural, por la soberanía popular y la división de poderes, por los derechos fundamentales y la tolerancia, por la pluralidad de partidos políticos y la independencia de los tribunales, se caracteriza por contar con una democracia pluralista o como sociedad abierta. Su constitución, entendida como un orden jurídico fundamental del Estado y de la sociedad, posee una validez jurídica

\footnotetext{
4 Rendón Gil, Raymundo. El Estado Constitucional de Derecho y los Derechos Humanos, http://www.tfjfa.gob.mx/investigaciones/pdf/estadoconstitucionaldederechoylosderechoshumanos.pdf. Fecha de acceso: 22 de agosto de 2015.

${ }^{5}$ Íbidem.

${ }^{6}$ Atienza, Manuel. El Derecho como Argumentación, Instituto de Investigaciones Jurídicas de la UNAM, http://biblio.juridicas.unam.mx/libros/4/1695/4.pdf. Fecha de acceso: 22 de agosto de 2015.

${ }^{7}$ Cfr. Íbidem.
} 
formal de naturaleza superior, la cual es creadora del momento, de la estabilidad y la permanencia. $^{8}$

En ese orden de ideas, la Dra. Ma. del Carmen Anaiga Vargas establece que el Estado Constitucional Democrático de Derecho se basa en la legitimidad de sus instituciones que es lo que le da su esencia, por lo que lo percibe como:

La intromisión práctica e ideal de su conjunto normativo en todas y cada una de las esferas del Estado y de la sociedad compuesta por ciudadanos con derechos, libertades y obligaciones. El Estado Constitucional presupone, entonces, la Constitución aceptada y compartida en libertad y democracia; democracia y libertad que a la vez tienen su base y protección en la Constitución misma. Implica, pues, legalidad, pero también legitimidad. Comprende tanto la autoridad estatal como la libertad individual y social. ${ }^{9}$

Es importante señalar que como su nombre lo indica, esta etapa del Estado de Derecho toma como cimiento la democracia, entendida no simplemente como una cuestión de reglas y procedimientos (de cómo tomar decisiones), sino que lo principal tiene que ver con el qué de las decisiones. Esto supone un respeto irrestricto y una expansión de los derechos fundamentales.

En ese sentido, la presente aportación se enfoca en el estudio del nuevo paradigma de la transparencia y la rendición de cuentas de los partidos políticos que trajo consigo la reforma política-electoral del 2014, reforma a partir de la cual, el Estado mexicano ha buscado superar las nuevas realidades políticas, económicas, sociales y culturales, que habían permitido que algunos entes que detentan el poder no estuviesen sujetos a las leyes y al derecho, violentando con ello al Estado Constitucional Democrático de Derecho.

Además, el país tenía una gran deuda con los ciudadanos y con las autoridades electorales, puesto que no las había dotado con las herramientas jurídicas suficientes para lograr sujetar a derecho a los partidos políticos, que como se observará en el presente trabajo, laceraban constantemente a la normatividad y a las instituciones electorales de México. Situación que cada vez, deslegitimaba más a las autoridades electorales y enardecía los ánimos de la ciudadanía que pide el fortalecimiento de la democracia y las instituciones normativas de nuestro país, puesto que como señala Federico Mayor Zaragoza: "si no hay evolución a tiempo, hay revolución con el riesgo de violencia que conlleva. La diferencia entre evolución y revolución es la «r» de responsabilidad" 10 .

En ese orden de ideas, la reforma constitucional en materia política-electoral del año 2014 llevada a cabo por el Estado mexicano busca consolidar y legitimar a las instituciones electorales de nuestro país ante la ciudadanía, y al mismo tiempo sujetar a derecho a los partidos políticos considerados como verdaderos poderes fácticos en el actual sistema electoral, social, político y económico de México, lo anterior con el otorgamiento de nuevas disposiciones normativas en materia de transparencia $y$

\footnotetext{
${ }^{8}$ Cfr. Häberle, Peter, El Estado Constitucional, "Concepto, fundamentación del objeto y métodos de trabajo", 1 ra reimpresión, México, UNAM, 2003, http://biblio.juridicas.unam.mx/libros/libro.htm?l=14. Fecha de acceso: 22 de agosto de 2015.

9 Anaiga Vargas, Ma. Del Carmen, Notas sobre el Estado Constitucional Democrático de Derecho, http://www.letrasjuridicas.com/Volumenes/7/ainaga7.pdf. Fecha de acceso: 22 de agosto de 2015.

10 Sampedro, José Luis otros. Reacciona, https://nomesesunblog.files.wordpress.com/2011/05/54771304-reacciona.pdf. Fecha de acceso: 25 de agosto de 2015.
} 
rendición de cuentas, que podrán ser utilizadas tanto por los ciudadanos, como por las autoridades electorales para lograr el respeto y un mejor ejercicio de la democracia mexicana. Puesto que basta con recordar que la transparencia es uno de los ejes rectores de la democracia, como claramente lo observa nuestro máximo órgano jurisdiccional en materia electoral y que ha quedado plasmado en diversos criterios jurisprudenciales. ${ }^{11}$

\section{LA REGULACIÓN DE LOS PARTIDOS POLÍTICOS EN MÉXICO}

La evolución del Estado Mexicano a través del tiempo impone nuevos retos y objetivos para el derecho, mismo que muchas veces se ve superado por la realidad, por lo que al ser la ley una expresión de las condiciones de la vida social y política, resulta indispensable hacerle frente a esas nuevas realidades mediante reformas constitucionales.

Así las cosas, específicamente en la materia política-electoral, el Estado Mexicano ha realizado grandes reformas a través del tiempo para afrontar las condiciones sociales que imponen nuevos desafíos para el Derecho. Toda vez que el Estado moderno presenta nuevos retos al ser mucho más sofisticado, diverso y complejo, presentándonos a lo largo de su evolución la aparición de poderes fácticos y el ascenso de los poderes constituidos que en el Estado tradicional no se presentaron, los cuales atentan contra el Estado Constitucional Democrático de Derecho que se busca alcanzar; y contra el principio de división de poderes entendido desde sus dos perspectivas, esto es la restringida y dogmática, y la flexible.

Por lo anterior es tarea de los poderes Legislativo y Ejecutivo de la Unión, restringir y sujetar a derecho a esos nuevos poderes fácticos y al ascenso de los poderes constituidos; realizándolo a lo largo de la historia a través de reformas constitucionales de gran trascendencia, que entre otras cosas, lograron la creación de los denominados Organismos Constitucionales Autónomos como entes capaces de sujetar a derecho a los nuevos poderes y frenar el ascenso de los poderes tradicionales, con la pretensión de crear un auténtico sistema de pesos y contrapesos.

De hecho, Montesquieu señalaba que: "El poder que no es limitado lleva necesariamente al abuso y a la arbitrariedad"; por lo que si el poder está distribuido entre distintos órganos que mutuamente se frenan, queda cerrada la posibilidad de que el poder constituido y los poderes fácticos se hagan ilimitados y soberanos.

\footnotetext{
${ }^{11}$ DETERMINANCIA. SE SATISFACE CUANDO EL JUICIO DE REVISIÓN CONSTITUCIONAL ELECTORAL VERSA SOBRE EL CUMPLIMIENTO DE LAS OBLIGACIONES DE LOS PARTIDOS POLÍTICOS EN MATERIA DE TRANSPARENCIA Y ACCESO A LA INFORMACIÓN PÚBLICA VINCULADAS AL PROCESO ELECTORAL. Tesis XLII/2015. Gaceta de Jurisprudencia y Tesis en materia electoral, Tribunal Electoral del Poder Judicial de la Federación, Año 8, Número 17, 2015, páginas 81 y 82.

ACCESO A LA INFORMACIÓN. LOS DATOS, NOMBRES Y SALARIOS CONTENIDOS EN LA PLANTILLA LABORAL DE UN PARTIDO POLÍTICO SON DE NATURALEZA PÚBLICA. Tesis VIII/2014. Gaceta de Jurisprudencia y Tesis en materia electoral, Tribunal Electoral del Poder Judicial de la Federación, Año 7, Número 14, 2014, páginas 33 y 34.
} 
En ese orden de ideas, en el presente apartado se aborda el estudio de las principales reformas constitucionales en materia política-electoral que, durante la segunda mitad del siglo XX, fueron realizadas por el Estado Mexicano, centrándonos en el tema principal que nos ocupa, esto es, en los Partidos Políticos, mismos que han atravesado por una serie de modificaciones, reformas y adiciones a lo largo de la historia de México, las cuales se han generado como consecuencia de diferentes circunstancias sociales, políticas y/o económicas que rebasaron al sistema normativo constitucional y pusieron en tela de juicio a la democracia, al sistema electoral y al sistema político mexicano.

Así por ejemplo, con el resultado de las elecciones del año 2000 que habían legitimado las instituciones y positivisado a la normatividad electoral, se vislumbraba que las elecciones del año 2006 se llevarían a cabo en un ambiente de tranquilidad y certidumbre, sin embargo, lo sumamente competidas que resultaron, evidenciaron las violaciones a la ley de la materia, que en algunos casos corrían el riesgo de convertirse en determinantes ${ }^{12}$; debido a que la diferencia entre el candidato ganador y quien obtuvo el segundo lugar fue de $0.56 \%$ de la votación total ${ }^{13}$, máxime que dichas elecciones se caracterizaron por un despilfarro obsceno de dinero, así como un uso y abuso excesivo de los medios de comunicación por parte de los Partidos Políticos, sus candidatos y organismos empresariales.

A causa de lo anterior, la normatividad electoral demostró tener vacíos legales que se debían colmar, pues nuevamente el Estado moderno con sus realidades sociales, económicas y políticas, habían superado al derecho, y no solo eso, nuevamente la normatividad electoral quedó trastocada, pues los ciudadanos entraron de nuevo en un ambiente de desconfianza e incertidumbre, respecto al proceso electoral, dando la puerta de entrada a una nueva reforma a las instituciones y normatividad política-electoral de México.

De manera que el Estado Mexicano impulsó otra reforma política-electoral que pretendió colmar las lagunas legales existentes, centrándose por lo tanto en temas específicos como lo eran: regulación de las precampañas; fortalecimiento de las atribuciones del otrora Instituto Federal Electoral (IFE) en materia de fiscalización de los Partidos Políticos que estaban resguardados en una "caja fuerte" por los secretos: bancario, fiduciario y fiscal; reducción de la prerrogativa de los Partidos Políticos del financiamiento público y el privado; reducción de las campañas electorales; así como regulación de los Partidos Políticos en el acceso a los medios de comunicación. ${ }^{14}$

Siendo los cambios trascendentales de la reforma constitucional en materia electoral del año 2007 los siguientes ${ }^{15}$ : a). Se prohibió la transmisión de propaganda gubernamental

\footnotetext{
${ }^{12}$ Entendida la determinancia como el conjunto de circunstancias que afectan sustancialmente principios rectores de la materia electoral y la certidumbre en el ejercicio personal, libre y secreto del voto, y que tal afectación, vicio o irregularidad tienen un impacto que afectan el resultado de la votación. Cfr. Morán Torres, Enoc Francisco, "La determinancia en el Derecho Procesal Electoral mexicano", en De la Madrid Andrade, Mario (Coord.) Derecho Procesal. Temas diversos, p., 160.

13 Córdova Vianello, Lorenzo, La reforma electoral y el cambio político en México, http://biblio.juridicas.unam.mx/libros/6/2527/17.pdf Fecha de acceso: 27 de agosto de 2015.

14 "ANÁLISIS COMPARATIVO DE LA REFORMA ELECTORAL CONSTITUCIONAL Y LEGAL 2007-2008", México, IFE, noviembre de 2008, http://www.ife.org.mx/documentos/Reforma_Electoral/docs/AC_RefElect0708.pdf. Fecha de acceso: 27 de agosto de 2015.

${ }^{15}$ Rodríguez Hernández, Edmundo Carlos, "La reforma constitucional electoral 2007 en México", México, UNAM, http://www.juridicas.unam.mx/publica/librev/rev/sufragio/cont/1/ens/ens11.pdf. Fecha de acceso: 27 de agosto de 2015.
} 
durante las campañas electorales y de manera absoluta la compra de publicidad electoral en los medios de comunicación; b). Se redujeron el periodo de las precampañas y campañas electorales, c). El entonces IFE se constituyó en la única autoridad electoral encargada de distribuir y asignar a los Partidos Políticos los tiempos en radio y televisión, por lo que se crea el Comité de Radio y Televisión; d). Se estableció un régimen sancionador con la finalidad de que los Partidos Políticos acaten las nuevas disposiciones electorales; e). Se destacó la obligación de los Partidos Políticos en materia de fiscalización y por primera vez en la materia de transparencia y acceso a la información pública; f). Reguló la liquidación de un Partido Político que no alcanzara el $2 \%$ de la votación para mantener su registro; g). Prohibió la participación de sociedades gremiales en la formación de Partidos Políticos, así como la afiliación corporativa de ciudadanos a los mismos; h). Reguló la posibilidad del Tribunal Electoral del Poder Judicial de la Federación (TEPJF) y del IFE de intervenir en la vida interna de los Partidos Políticos para garantizar el respeto a la normatividad electoral, a la transparencia y acceso a la información, y a la democracia.

Prosiguiendo en la línea argumentativa, con la reforma en comento, se esperaba que las elecciones del 2012 se realizaran sin mayores irregularidades y sobresaltos, y aunque no fueron tan competidas y reñidas como las anteriores elecciones, al menos en el aspecto de los resultados de la votación, se continuó con el mismo problema que violaba a la normatividad electoral, esto es, el financiamiento de los Partidos Políticos, situación que permitió advertir que el sistema de transparencia y fiscalización impuesto a los Partidos Políticos en la reforma del año 2007, entre otras cosas, continuaban siendo imperfecto y contenía serias lagunas que permitían la existencia de puertas de escape para los Partidos Políticos, las cuales fueron aprovechadas por los mismos, transformando la competencia electoral en inequitativa. Por lo que, la aprobación de una nueva reforma en materia política-electoral era inminente.

\section{LA REFORMA MEXICANA EN MATERIA POLÍTICA-ELECTORAL 2014}

Antes de iniciar con el estudio de la Reforma Constitucional en materia políticaelectoral del año 2014, es importante destacar la promulgación de otras reformas y leyes que guardan gran relación con el presente trabajo, que juntas conforman lo que llamamos la sistematización legislativa, entendida como la actividad ordenada, sistemática y metódica realizada por los órganos encargados de la función legislativa, los cuales mediante la expedición de normas, leyes y reformas, garantizan y aseguran la eventual aplicación y observancia de reformas, leyes y normas posteriores.

En esa tesitura, las reformas, leyes y normas que garantizan la eventual aplicación de la Reforma Política-Electoral del año 2014 en materia de Transparencia y Fiscalización de los Partidos Políticos, son la reforma constitucional en materia de Derechos Humanos del año 2011, la promulgación en el año 2012 de la Ley Federal para la Prevención e Identificación de Operaciones con Recursos de Procedencia Ilícita y su Reglamento en el año 2013, la reforma Hacendaria del año 2013, y la reforma constitucional en materia de Transparencia del año 2014, solo por mencionar algunas.

La reforma en materia de Derechos Humanos llevada a cabo por el Congreso de la Unión, y publicada en el Diario Oficial de la Federación (DOF) el 10 de junio de 2011, 
viene a modificar toda la perspectiva normativa del Estado mexicano y de la actividad jurisdiccional, pues entre otras cosas, uno de los cambios que trajo consigo fue que integró al régimen normativo interno a los Tratados Internacionales de los que el Estado mexicano sea parte, y por ende, el control de convencionalidad y la interpretación conforme. Asimismo estableció el principio pro persona ${ }^{16}$.

Por lo que en la materia de transparencia, en lo que se refiere a los Partidos Políticos, si la normatividad electoral y la Carta Magna contienen lagunas, los ciudadanos pueden recurrir a la normatividad internacional, en otras palabras a los Tratados Internacionales de los que México sea parte, para hacer efectivo su derecho de acceso a la información pública, si estos regulan aspectos relacionados con esta materia. Incluso si la normatividad electoral a excepción de nuestra Carta Magna, establece mayores límites y restricciones para acceder al derecho humano en materia de Transparencia, y los Tratados Internacionales los maximizan, en virtud del principio pro persona, se aplicarán éstos por encima de aquella.

Así, la eventual aplicación y observancia de la Reforma Política-Electoral del año 2014 en materia de Transparencia y Fiscalización de los Partidos Políticos, debería estar garantizada.

En ese orden de ideas, el 17 de octubre de 2012 fue publicado en el DOF, el Decreto por el que se expide la Ley Federal para la Prevención e Identificación de Operaciones con Recursos de Procedencia Ilícita. Ley que posteriormente fue dotada de operatividad con la publicación en el DOF, el 16 de agosto de 2013 del Reglamento correspondiente.

De lo anterior se desprende que la Ley y su Reglamento, garantizan la eventual aplicación y respeto de las disposiciones en materia de transparencia y sobretodo de fiscalización de los Partidos Políticos contenidas en la Reforma Política-Electoral del año 2014, disposiciones que más adelante expondremos con detalle; toda vez que los Partidos Políticos son entidades de interés público que por su ocupación, actividad y objeto social son susceptibles de realizar las actividades vulnerables establecidas por la Ley Federal para la Prevención e Identificación de Operaciones con Recursos de Procedencia Ilícita, y por ende no solamente estarán vigilados por el Instituto Nacional Electoral (INE), sino también por la Secretaría de Hacienda y Crédito Público (SHCP) a través del Servicio de Atención Tributaria (SAT) y la Unidad de Inteligencia Financiera así como la Procuraduría General de la República a través de su Unidad Especializada en Análisis Financiero.

Avanzando en nuestro razonamiento, el Estado Mexicano en el año 2013 llevó a cabo la Reforma en materia Hacendaria, destacando de la misma la implementación de un sistema informático abierto, que entre otras cosas permitirá a los contribuyentes rendir sus declaraciones en tiempo y forma; previó la facultad de los Proveedores Autorizados Certificados para emitir facturas electrónicas; estableció el uso generalizado y obligatorio del Comprobante Fiscal Electrónico por Internet o Comprobante Fiscal Digital por Internet, el cual mejora el proceso de fiscalización y permite combatir el uso de facturas falsas, simulación de operaciones y la sub-declaración de impuestos.

\footnotetext{
${ }^{16}$ Diario Oficial de la Federación, "Decreto por el que se modifica la denominación del Capítulo I del Título Primero y reforma diversos artículos de la Constitución Política de los Estados Unidos Mexicanos" 10 de junio de 2011, http://dof.gob.mx/nota_detalle.php?codigo=5194486\&fecha=10/06/2011. Fecha de acceso: 5 de septiembre de 2015.
} 
De lo anterior, se desprende que tanto las autoridades electorales, como las demás que intervengan en los procesos de fiscalización de los Partidos Políticos, gracias a la reforma en comento, cuentan con una nueva herramienta y mecanismo que ayudará a simplificar sus actividades de fiscalización y rendición de cuentas, garantizando la eventual aplicación de las obligaciones que impone a los Partidos Políticos la reforma política-electoral del año 2014 en materia de transparencia y fiscalización.

El origen del largo camino recorrido en búsqueda de transparencia en la rendición de cuentas e información pública en México, se remonta al año de 1977, cuando por decreto publicado en el DOF de fecha 6 de junio se reformó el artículo $6^{\circ}$ constitucional, incluyendo en dicho numeral el derecho a la información y la obligación del Estado de garantizarlo. Pese a las diversas interpretaciones que pudieron haber surgido respecto del alcance de este derecho, lo cierto es que desde 1948, en la Declaración de los Derechos del Hombre y del Ciudadano, ha sido considerado como un derecho humano.

A partir de entonces, los esfuerzos por legislar y progresar en la materia no tuvieron sustancial trascendencia sino hasta el año de 2002 en el que se expidió la Ley Federal de Transparencia y Acceso a la Información Pública Gubernamental ${ }^{17}$ y con ella se da origen a la creación del entonces Instituto Federal de Acceso a la Información y Protección de Datos, entonces IFAI. Bajo esta tendencia generalizada de clarificación de los asuntos de interés nacional, el 23 de mayo del año de 2014, se expide la LGPP en la cual se incluye en su Título Segundo un capítulo específico denominado "De las Obligaciones de los Partidos Políticos en Materia de Transparencia."

En consecuencia, una de las reformas de mayor trascendencia y vinculación con la Reforma Política-Electoral del año 2014 en el tema de la fiscalización y transparencia de los Partidos Políticos, fue la que se publicó en el DOF el 7 de febrero de 2014, en la que se destaca lo siguiente ${ }^{18}$ : a) La creación del IFAI como un organismo constitucional autónomo; competente para conocer de los asuntos relacionados con el acceso a la información pública y la protección de datos personales de cualquier autoridad, órgano y otras entidades, destacando entre ellas los Partidos Políticos; b) La información en posesión de diversas autoridades y organismos, entre los que se encuentran los Partidos Políticos, es pública y sólo podrá ser reservada temporalmente por razones de interés público y seguridad nacional, en los términos que fijen las leyes; considerando que en la interpretación de este derecho deberá prevalecer el principio de máxima publicidad; c) La obligación impuesta a los Partidos Políticos, va en función a que éstos deberán preservar sus documentos en archivos administrativos actualizados, asimismo deberán publicar, a través de los medios electrónicos disponibles, la información completa y actualizada sobre el ejercicio de los recursos públicos y los indicadores que permitan rendir cuenta del cumplimiento de sus objetivos y de los resultados obtenidos.

De igual forma se establece que el IFAI deberá coordinar sus acciones con la entidad de fiscalización superior de la Federación, con la entidad especializada en materia de archivos y con el organismo encargado de regular la captación, procesamiento y publicación de la información estadística y geográfica, así como con los organismos

\footnotetext{
${ }^{17}$ Abrogada el 9 de mayo de 2016 en virtud de la entrada en vigor de la Ley Federal de Transparencia y Acceso a la Información Pública.

${ }^{18}$ Diario Oficial de la Federación, "Decreto por el que se reforman y adicionan diversas disposiciones de la Constitución Política de los Estados Unidos Mexicanos, en materia de Transparencia", 07 de febrero de 2014, http://dof.gob.mx/nota_detalle.php?codigo $=5332003 \&$ fecha=07/02/2014. Fecha de acceso: 5 de septiembre de 2015.
} 
garantes de los estados y el Distrito Federal ${ }^{19}$, con el objeto de fortalecer la rendición de cuentas del Estado Mexicano; a las cuales se le deberán de agregar la Comisión de Fiscalización y la Unidad Técnica de Fiscalización del INE; la SHCP a través del SAT y de la Unidad de Inteligencia Financiera; y la Procuraduría General de la República a través de su Unidad Especializada en Análisis Financiero.

Por todo lo anterior, es evidente la estrecha relación y vinculación entre la reforma en materia de trasparencia y las disposiciones en materia de fiscalización y transparencia de los Partidos Políticos que estableció la reforma en materia política-electoral del año 2014; así como la sistematización legislativa que garantiza la eventual aplicación y positividad de las disposiciones en materia de fiscalización y transparencia de los Partidos Políticos de la reforma política-electoral en comento.

Una vez apuntado lo anterior, el Decreto por el que se reforman, adicionan y derogan diversas disposiciones de la Constitución Política de los Estados Unidos Mexicanos, en materia política-electoral, fue publicado en el DOF el 10 de febrero de 2014, gracias al surgimiento de un acuerdo político sui generis y excluyente de la ciudadanía, un pacto entre los Partidos Políticos con mayor fuerza electoral denominado "Pacto por México", del cual no abundaremos en el tema, pues sería objeto de una extensa investigación. ${ }^{20}$

La reforma en comento, planteaba regular los diferentes problemas y conflictos que surgieron en las elecciones del año 2012, esto es, la fiscalización de los recursos tanto privados como públicos de los partidos políticos; la transparencia de los mismos; modificación en la estructura y competencia del otrora IFE; entre otros aspectos, trayendo consigo los principales cambios $^{21}$ : a) Se adiciona en el artículo 35 de la Constitución el derecho de los ciudadanos a iniciar leyes, en los términos y con los requisitos que señalen dicha Constitución y la Ley del Congreso. El INE tendrá las facultades que en esta materia le otorgue la ley. Figura que se reguló de manera más amplía mediante la publicación del Decreto por el que se reforman y adicionan diversas disposiciones de la Ley Orgánica del Congreso General de los Estados Unidos Mexicanos, de la Ley General del Sistema de Medios de Impugnación en Materia Electoral, de la Ley Orgánica de la Administración Pública Federal y del Código Federal de Instituciones y Procedimientos Electorales en materia de Iniciativa Ciudadana e Iniciativa Preferente. Publicado en el DOF el martes 30 de mayo de 2014; b) La implementación y regulación de la figura de participación ciudadana denominada consulta popular en temas de trascendencia nacional. Las cuales podrán ser convocadas por el Congreso de la Unión a petición ya sea del Presidente de la República, del 33\%

\footnotetext{
${ }^{19}$ Diario Oficial de la Federación, "Decreto por el que se declaran reformadas y derogadas diversas disposiciones de la Constitución Política de los Estados Unidos Mexicanos, en materia de la reforma política de la Ciudad de México", 29 de enero de 2016, http://dof.gob.mx/nota_detalle.php?codigo=5424043\&fecha=29/01/2016. Fecha de acceso: 9 de junio de 2016.

${ }^{20}$ El Pacto por México es una acción concentrada en un grupo de poder, los partidos políticos con mayor fuerza nacionales con mayor fuerza electoral en el país, mismo que consistió en cinco grandes acuerdos que comprenden los ejes considerados sustanciales para el desarrollo de México. Cfr. Jiménez Díaz Antonio y Morán Torres Enoc Francisco, "Los pactos entre líderes de fuerzas políticas, experiencias iberoamericanas. El desafío de la democracia participativa en la construcción de un proyecto de Estado Constitucional y Democrático de Derecho" en Vidaurri Aréchiga Manuel et al., (coords.) Conciencia jurídica Mexicana, México, Porrúa, 2014.

${ }^{21}$ Diario Oficial de la Federación, "Decreto por el que se reforman, adicionan y derogan diversas disposiciones de la Constitución Política de los Estados Unidos Mexicanos, en materia política-electoral", 10 de febrero de 2014, http://dof.gob.mx/nota_detalle.php?codigo=5332025\&fecha=10/02/2014. Fecha de acceso: 5 de septiembre de 2015 .
} 
de los mismos integrantes de cualquiera de las Cámaras del Congreso de la Unión y por el $2 \%$ de los ciudadanos inscritos en la lista nominal de electores. Asimismo la consulta popular se realizará el mismo día de la jornada electoral y su ejercicio y desarrollo será regulado por el INE; c) Se establece un nuevo porcentaje que tendrán que cubrir los Partidos Políticos federales para mantener su registro el cual es el tres por ciento del total de la votación válida emitida en cualquiera de las elecciones que se celebren para la renovación del Poder Ejecutivo o de las Cámaras del Congreso de la Unión; d) Aparece por primera vez regulado la prerrogativa a que tendrán derecho los candidatos independientes para las campañas electorales en los términos que establezca la LEGIPE; e) El cambio en la denominación, integración y facultades del IFE ahora denominado INE, así como el cambio en la denominación, integración y facultades de los Institutos Electorales Locales ahora Organismos Públicos Electorales Locales (OPLES); f) Se le otorgan nuevas funciones y competencias a los órganos electorales que son los encargados de las elecciones locales en las entidades federativas: Derechos y el acceso a las prerrogativas de los candidatos y Partidos Políticos; Educación Cívica; Preparación de la jornada electoral; Impresión de documentos y la producción de materiales electorales; Escrutinios y cómputos; Declaración de validez y el otorgamiento de constancias en las elecciones locales; Cómputo de la elección del titular del poder ejecutivo; Resultados preliminares; encuestas o sondeos de opinión; observación electoral, y conteos rápidos; Organización, desarrollo, cómputo y declaración de resultados en los mecanismos de participación ciudadana que prevea la legislación local; g) Se establece que el INE podrá asumir mediante convenio con las autoridades competentes de las entidades federativas que así lo soliciten, la organización de procesos electorales locales, en los términos que disponga la legislación aplicable; $h$ ) Nueva facultad del INE para designar y remover a los integrantes del órgano superior de dirección de los Organismos Públicos Locales; i) Se establecen las funciones y atribuciones del INE tanto para los procesos electorales Locales y Federales; j) Se establecen nuevas causales de nulidad de elecciones tanto a nivel federal como a nivel local por violaciones graves, dolosas y determinantes, cuando: Se exceda el gasto de campaña en un cinco por ciento del monto total autorizado; Se compre cobertura informativa o tiempos en radio y televisión, fuera de los supuestos previstos en la ley; se reciban o utilicen recursos de procedencia ilícita o recursos públicos en las campañas; $\mathrm{k}$ ) Nueva forma de asignación de diputados de representación proporcional, pues ahora todo Partido Político que alcance por lo menos el tres por ciento del total de la votación válida emitida para las listas regionales de las circunscripciones plurinominales, tendrá derecho a que le sean atribuidos diputados según el principio de representación proporcional; 1) Cambio en la fecha para la celebración de la jornada electoral el primer domingo de junio, ya no de julio; $m$ ) Se establece la figura de la Elección inmediata o reelección establecida y reglamentada de la siguiente manera: Para los Senadores la elección inmediata se podrá realizar hasta por dos periodos consecutivos, para completar 12 años en el ejercicio; mientras que para los Diputados del Congreso de la Unión, hasta por cuatro periodos consecutivos para poder completar 12 años en el ejercicio; n) Nuevo procedimiento para la designación de los Magistrados Electorales de los Tribunales Locales, ahora serán electos por las dos terceras partes de los miembros presentes de la Cámara de Senadores, previa convocatoria pública; o) Nuevo porcentaje que tendrán que cubrir los Partidos Políticos locales para mantener su registro, el cual es el tres por ciento del total de la votación válida emitida en cualquiera de las elecciones que se celebren para la renovación del Poder Ejecutivo o Legislativo locales; p) Se crea la Fiscalía General de la República. 
Mención particular merecen los artículos transitorios de la Reforma de referencia, ya que los mismos presentan un sin número de claroscuros y contradicciones, que merecerían un análisis y un trabajo de investigación aparte. Por lo que sólo haremos mención al artículo segundo transitorio, pues del mismo se desprende la ley que contiene los principales cambios en materia de Partidos Políticos.

De manera que el artículo segundo transitorio del Decreto en comento, plantea la expedición por parte del Congreso de la Unión de una serie de leyes que darían operatividad y funcionalidad a la reforma constitucional, las cuales son las siguientes: Ley General de Instituciones y Procedimientos Electorales, publicada en el DOF el 23 de mayo de 2014; LGPP publicada en el DOF el 23 de mayo de 2014; Ley General en Materia de Delitos Electorales, publicada en el DOF el 23 de mayo de 2014.

Siendo entonces la LGPP el objeto del presente trabajo de investigación, toda vez que es el dispositivo legal que regula ampliamente a los Partidos Políticos, estableciendo un sin número de disposiciones de gran importancia.

\section{LA FISCALIZACIÓN Y TRANSPARENCIA DE LOS PARTIDOS POLÍTICOS EN MÉXICO}

En materia de transparencia y acceso a la información en los Partidos Políticos es un tema y una materia en la cual el Estado mexicano había tomado como base el principio de la no intromisión de las autoridades en la vida interna de los Partidos Políticos, sin embargo como hemos podido constatar en supralíneas las entidades de interés público en comento, han usado el mencionado principio para acumular poder y para violar la normatividad electoral, en perjuicio de la ciudadanía y de la democracia; afectando, como hemos observado a lo largo del presente trabajo, entre otras cosas, la equidad en las contiendas electorales, al grado de que algunos autores afirman que han transformado al sistema de partidos en nuestro país, en una partidocracia.

De ahí que, sea factible la interrogante: ¿qué trascendencia tiene la transparencia y la fiscalización de los Partidos Políticos, para la democracia y la equidad de los procesos electorales?, la respuesta es quizá: sumamente importante, sobre todo si en el Estado Mexicano se pretende evolucionar al Estado Constitucional Democrático de Derecho, puesto que garantizar el respeto de los derechos en materia de transparencia con los que cuentan los ciudadanos permite que sean ellos mismos los que juzguen de manera informada y consciente a los Partidos Políticos y a los candidatos a través del sufragio.

Como decía Ferenjohn "nada golpea más vigorosamente a la democracia que la escasez de información que la mayoría de la gente tiene acerca de la política" ${ }^{22}$, o Madison quien advertía que "un gobierno democrático sin información popular o la posibilidad de adquirirla, es el prólogo de una farsa o una tragedia o ambas" ${ }^{23}$, sobre todo si tenemos en cuenta lo expresado por Presno Linera, quien manifiesta que "el nuevo auge de los movimientos sociales durante la segunda década del siglo XXI, con toda su heterogeneidad, sus contradicciones y problemas internos, es el afán de centenares de miles de personas por independizarse del corsé en el que se sienten constreñidas por

\footnotetext{
${ }^{22}$ Chacón Rojas, Oswaldo, "Informe de labores de funcionarios públicos y la garantía de equidad en las contiendas", Temas selectos de Derecho Electoral. México, 2013, p. 24.

${ }^{23}$ Ídem.
} 
unas instituciones de gobierno y unas organizaciones políticas anquilosadas y con discursos caducos, y el deseo de interactuar por medio del discurso con otras personas, experimentando así también la dificultad inherente a la toma de decisiones que nos afectan a todos."24

En ese orden de ideas y citando a Manin la ignorancia ciudadana pone en peligro las razones instrumentales de la democracia como un régimen que sirve a los intereses de la mayoría, toda vez que abre potencialmente la puerta a la manipulación de los políticos y de los Partidos Políticos, ${ }^{25}$ y no solo pone en peligro las razones instrumentales de la democracia de la manera como lo afirmaba Manin, sino que también la pone en peligro de tal manera que los multireferidos partidos, con el margen de maniobra que le otorgaba ese aferrado dogma de la inviolabilidad de su vida interna, se han degenerado y transformado de ser esos entes de interés social mediante los cuales los ciudadanos pueden acceder a cargos de representación popular y formar parte de las decisiones y del gobierno de nuestro país, en entes de interés puramente individual y particular, los cuales al ser hoy en día verdaderos poderes fácticos en la realidad social, económica y política de nuestro país, amasan poder, influencias y riqueza, para sus propios fines y propósitos; pues no se contaban con los instrumentos y normatividad suficiente para hacerlos rendir cuentas ante la ciudadanía y ante los Organismos Constitucionales Autónomos, pues como bien lo señala Moretón Toquero, no se debe olvidar que en un Estado democrático de Derecho "la publicidad sirve, con carácter general, para alcanzar la transparencia que permite que los ciudadanos pueden visibilizar el funcionamiento de las Administraciones y, en general, el ejercicio del poder público, lo que cumple, en primer término, una misión evidente: la de permitir el control de dicha actividad y su sometimiento a la legalidad limitando la arbitrariedad, exigencia consustancial al Estado de Derecho." 26

Siendo de suma importancia destacar lo expresado por el Comisionado del INAI, Francisco Javier Acuña Llamas, en referencia al alcance de la reforma en materia de transparencia descrita en supralíneas, y al margen de los trabajos para la expedición de una nueva Ley de Transparencia; estableciendo que "los partidos políticos deben ser permeables a la transparencia toda vez que la desconfianza ciudadana hacia ellos vulnera la credibilidad de nuestro sistema democrático", por lo que "conocer a fondo su vida interna permitirá a la ciudadanía poder participar activamente e involucrarse en sus actividades" 27 , lo expresado por el comisionado se complementa con lo enunciado por Moretón Toquero, quien manifiesta que la transparencia, entre sus diversas finalidades, cumple la de "servir de cauce de profundización en la dimensión democrática del Estado mejorando la posibilidad de participación de los ciudadanos en los asuntos

\footnotetext{
${ }^{24}$ Fresno Linera, Miguel Ángel, "Partidos políticos y movimientos ciudadanos en la sociedad del riesgo y la desconfianza", Junta General del Principado de Asturias, 2014, p. 249.

${ }^{25}$ Ibídem, p. 25

${ }^{26}$ Moretón Toquero, Arancha, "Los límites del derecho de acceso a la información pública", Revista Jurídica de Castilla y León. N..$^{\circ}$ 33. Junta de Castilla y León. mayo 2014. MONOGRÁFICO TRANSPARENCIA, ACCESO A LA INFORMACIÓN PÚBLICA Y BUEN GOBIERNO ANÁLISIS DE LA CUESTIÓN TRAS LA LEY 19/2013.

${ }^{27}$ Acuña Llamas, Javier, "Conferencia magistral Alcance de la Reforma en Materia de Transparencia: El tema de los Partidos Políticos. Comisión de Acceso a la Información Pública y Protección de Datos Personales del estado de Tlaxcala”, México, 2013, http://inicio.ifai.org.mx/Comunicados/Comunicado\%20IFAI-070-14.pdf. Fecha de acceso: 8 de septiembre de 2015.
} 
públicos, e implementar la dimensión democrática del Estado sobre la base de una ciudadanía mejor informada." 28

De lo anterior, se puede desprender que la transparencia en los Partidos Políticos permite un doble mecanismo de control, pues por una parte los organismos constitucionales autónomos y demás autoridades, cuentan con la reforma del año 2014, con la sistematización legislativa explicada en supralíneas, y específicamente con la LGPP, con los mecanismos suficientes para sujetar a derecho a los Partidos de mérito; asimismo los ciudadanos gracias a las nuevas disposiciones en materia de transparencia, podrán a través de la emisión del sufragio en las urnas electorales, ejercer un control sobre los referidos partidos, premiándolos o castigándolos a través de su voto e incluso puedan participar en lo que López de la Cuesta define como "gobierno abierto", que según la referida autora, "consiste fundamentalmente en abrir, a través de Internet, la gestión de los asuntos públicos a los ciudadanos, de forma que estos puedan, de una parte, tener un mayor conocimiento, información y control sobre las actuaciones de los políticos y gestores públicos, y de otra intervenir, colaborar y participar en la gestión pública." 29

Ahora bien, ¿cuáles son las nuevas obligaciones en materia de transparencia y rendición de cuentas con las que deben cumplir los partidos políticos?; además de las disposiciones que plantean los Tratados Internacionales gracias a la reforma del año 2011; de las disposiciones que plantea la Ley para la Prevención e Identificación de Operaciones con Recursos de Procedencia Ilícita y su Reglamento; y las disposiciones en materia de transparencia que establece la Reforma en materia de transparencia del año 2014 y la Ley General de Transparencia y Acceso a la Información Pública; deberán de cumplir con las disposiciones que establece la LGPP.

Antes de exponer las disposiciones en materia de transparencia y fiscalización de los Partidos Políticos es importante destacar un artículo de la LGPP, el cual es crucial para darle operatividad a las disposiciones de la ley referida en las materias de transparencia y fiscalización de los multireferidos partidos. Disposición que viene a romper el principio dogmático señalado en supralíneas del respeto a la vida interna de los Partidos Políticos y que había hecho fracasar a la gran mayoría de reformas en materia política y electoral, pues por primera vez se establece que los referidos partidos deben estar conformados por ciertos órganos, que serán los encargados de respetar determinadas materias y disposiciones de su normatividad interna. En efecto los Partidos Políticos deberán contar como mínimo con los siguientes Órganos Internos, entre los que se encuentra un órgano encargado de cumplir con las obligaciones de transparencia y acceso a la información, mismos que debieron estar integrados a más tardar el 30 de septiembre de 2014.

Una vez señalado lo anterior, las principales disposiciones en materia de transparencia que establece la LGPP son las siguientes: permitir la práctica de auditorías y verificaciones, así como la entrega de la documentación que les sea requerida en materia de ingresos y egresos los órganos del Instituto facultados para ello, o de los Organismos Públicos Locales cuando se deleguen en éstos las facultades de fiscalización, así como la obligación de cumplir con sus obligaciones en materia de transparencia y acceso a su

\footnotetext{
${ }^{28}$ Moretón Toquero, Arancha, Op. cit.

${ }^{29}$ López de la Cuesta, Marta. Actuaciones en materia de transparencia y gobierno abierto en Castilla y León. REVISTA JURÍDICA DE CASTILLA Y LEÓN. N. ${ }^{\circ}$ 33. Junta de Castilla y León. MAYO 2014. MONOGRÁFICO TRANSPARENCIA, ACCESO A LA INFORMACIÓN PÚBLICA Y BUEN GOBIERNO ANÁLISIS DE LA CUESTIÓN TRAS LA LEY 19/2013.
} 
información; respetar las disposiciones de la Ley en materia de transparencia y acceso a la información, asimismo se establece la competencia del INAI para conocer de los asuntos relacionados con la transparencia, acceso a la información y protección de datos relacionados con los referidos partidos; publicar en sus páginas de internet para el público en general lo siguiente: Documentos básicos; Padrón de sus militantes, conteniendo exclusivamente el apellido paterno, materno, nombre o nombres, fecha de afiliación y entidad de residencia; Contratos y convenios suscritos para la adquisición, arrendamiento, concesiones y prestación de bienes y servicios, entre otros, implementando la denominada publicidad activa, la cual, según el autor español Manuel Villoria, "se diferencia del derecho de acceso en la actitud de los poderes públicos a la hora de aportar datos a la ciudadanía. En la publicidad activa, el gobierno pone los datos a disposición de la ciudadanía, en portales y páginas web, sin esperar a que los ciudadanos los demanden, proactivamente." 30

Aunado a lo anterior, la información que será considerada como reservada son los procesos deliberativos de los órganos internos del partido; La relativa a sus estrategias políticas; las actividades de naturaleza privada, familiar, personal de sus militantes, dirigentes, precandidatos y candidatos a cargos de elección popular.

En ese orden de ideas, antes de exponer las disposiciones en materia de fiscalización que establece la LGPP, es importante señalar el sistema de contabilidad y el régimen financiero con el que los Partidos Políticos deberán contar, que la misma Ley establece, sistema y régimen que junto con el Comprobante Fiscal Electrónico por Internet o Comprobante Fiscal Digital por Internet que estableció la Reforma en materia Hacendaria del año 2013 expuesta en supra líneas, simplificarán las labores de las Autoridades fiscalizadoras competentes. Por lo que sus obligaciones son: para el financiamiento privado los Partidos Políticos deberán de expedir recibos foliados en el que aparezca el nombre completo y domicilio, Clave de elector y, en su caso Registro Federal de Contribuyentes del aportante; $\mathrm{Si}$ la aportación se realiza con cheque o transferencia bancaria, la cuenta de origen deberá estar a nombre del aportante. Con la finalidad de que el Partido Político pueda cumplir con su obligación de entregar una relación mensual de los nombres de los aportantes. Las aportaciones o cuotas deberán depositarse en cuentas bancarias a nombre del Partido Político.

Además, se establece la estrecha y coordinada relación que deberán tener la SHCP, a través de su unidad administrativa competente en materia de inteligencia financiera; La Fiscalía General de la República; y el INE a través de su Unidad Técnica de Fiscalización; para localizar e identificar los recursos de procedencia ilícita aportados a los Partidos Políticos, además de que se deberán respetar y acatar las disposiciones establecidas en la Ley Federal para la Prevención e Identificación de Operaciones con Recursos de Procedencia Ilícita y su Reglamento.

Aunado a lo anterior, se establece que el INE deberá garantizar la máxima publicidad de los registros y movimientos contables, avisos previos de contratación y requerimientos de validación de contrataciones respecto de los Partidos Políticos, coaliciones y candidatos. Además, la Ley en comento contempla cuatro tipos de informes que deberán rendir los Partidos Políticos a la Unidad Técnica de Fiscalización del INE, a través de su Órgano responsable de la administración del patrimonio y recursos financieros, y de la presentación de los informes de ingresos y egresos trimestrales y anuales, de

\footnotetext{
${ }^{30}$ Villoria, Manuel, La publicidad activa en la Ley de Transparencia, Acceso a la Información y Buen Gobierno: posibilidades e insuficiencias, Universidad Rey Juan Carlos, p. 9.
} 
precampaña y campaña. Que será formado según lo establezcan los propios Partidos Políticos. Siendo la autoridad encargada de la revisión de los informes que los Partidos Políticos presenten sobre el origen y destino de sus recursos ordinarios y de campaña, así como de la práctica de auditorías sobre el manejo de sus recursos y su situación contable y financiera, es el Consejo General del INE, a través de su Comisión de Fiscalización la cual estará a cargo de la elaboración y presentación al Consejo General del dictamen consolidado y proyecto de resolución de los diversos informes.

Finalmente, se establece la facultad con la que cuentan en todo momento el Consejero Presidente, los Consejeros Electorales y el Secretario Ejecutivo de INE para solicitar en todo momento informes sobre los gastos ordinarios de los Partidos Políticos nacionales y locales a la Comisión de Fiscalización. Asimismo en cuanto a los informes de precampaña y campaña, la Comisión de Fiscalización dará en sesión privada a los Consejeros Electorales un informe cada veinticinco días de los avances de las revisiones.

Sin embargo, el panorama nacional respecto de los alcances del derecho a la información y la corresponsabilidad estatal de garantizarlo y promoverlo que éste lleva inmersa, se ha visto fundamentalmente transformado con la expedición de la nueva Ley General de Transparencia y Acceso a la Información Pública (LGTAIP) publicada en el DOF el 4 de mayo de 2015. Entre los cambios más significativos que esta disposición ha venido a implementa, se encuentran los sujetos que se considerarán obligados, entre ellos los Partidos Políticos, el carácter de autónomo del IFAI ahora INAI, sus facultades en la resolución de recursos y los alcances de las mismas.

En cuanto a los sujetos obligados, la anterior ley en materia de transparencia solo señalaba como tales a los Poderes de la Unión, órganos constitucionales autónomos o entidades federales. Sin embargo, a partir del pasado 4 de mayo con esta nueva Ley de Transparencia, también serán obligados los Partidos Políticos, fideicomisos y fondos públicos, así como cualquier persona física, moral o sindicato que reciba y ejerza recursos públicos; dicha obligatoriedad es esencial, puesto que como lo afirman Rodríguez López y Fidalgo Cerviño, para alcanzar el objetivo de credibilidad que sustenta la función legitimadora de los partidos políticos, "parece bastante razonable que los partidos políticos estén sujetos a un grado de transparencia informativa adecuado y conveniente en el ámbito de sus actividades y relaciones económicas que, lejos de constreñirlos, incrementen el nivel de fiabilidad y confianza en los mismos; y todo ello, puede alcanzarse con un modelo o sistema de financiación y de registro de información económica y financiera coherente y apropiado, respectivamente."31

Si bien es cierto, que en la LGPP se establecía ya la obligación de los mismos de atender a las disposiciones en materia de transparencia establecidas por la ley respectiva, y también se señala de manera explícita el deber de brindar públicamente la información que les fuere solicitada, como lo pueden ser sus documentos básicos, organización y reglamentos internos, el padrón de militantes, la remuneración de sus directivos, los montos del financiamiento público que reciben, informes respecto de egresos e ingresos, así como las resoluciones de órganos jurisdiccionales en los que el partido sea parte del proceso, entre otras.

Con la nueva LGTAIP, dichas responsabilidades se han ampliado, estableciendo una serie de obligaciones comunes para todos los sujetos obligados así como otras

\footnotetext{
${ }^{31}$ Rodríguez López Ángel y Fidalgo Cerviño Esther, "Transparencia y credibilidad: el caso de los partidos políticos en España”, Partida Doble, núm. 218, páginas 18 a 24.
} 
específicas. En cuanto a las primeras, de manera general podrá decirse que incluyen lo relacionado con la publicidad de su estructura orgánica integral señalando las funciones de cada miembro, sus programas operativos, un directorio en el que se especifiquen cargos, datos personales; la remuneración a sus integrantes, incluyendo no solo el sueldo base, sino también prestaciones, gratificaciones, comisiones, dietas, bonos, viáticos, entre otros; la información de los programas de subsidios, estímulos y apoyos, especificando la manera en que son distribuidos y ejercidos; así también la información curricular desde el equivalente a un jefe de departamento hasta el titular del partido; datos financieros sobre presupuesto asignado, así como los informes del ejercicio trimestral del gasto; los resultados de las auditorías que les sean realizadas; el inventario de bienes muebles e inmuebles en posesión y propiedad, entre otros.

En cuanto a las obligaciones específicas, éstas se encuentras establecidas en el artículo 76 de la LGTAIP, el cual dispone que además de las obligaciones comunes los Partidos Políticos nacionales y locales deberán poner a disposición del público y actualizar la información relacionada con el padrón de afiliados o militantes; acuerdos y resoluciones de los órganos de dirección; convenios de participación con organizaciones de la sociedad civil; las minutas de las sesiones; especificar quienes son los responsables de los órganos internos de finanzas; montos de las cuotas aportadas por militantes; listado de aportantes a las precampañas y campañas políticas; el currículo de los candidatos a cargos de elección popular que debe de incluir fotografía y el cargo al que aspira; convenios de frente, coalición o fusión; responsables de la selección de candidatos a cargos de elección popular; recursos destinados al desarrollo del liderazgo de las mujeres; mecanismos de control y de los procesos internos de selección de candidatos.

Así pues, las obligaciones, tanto comunes como específicas, que constriñen a los Partidos Políticos, no se quedan en meros enunciados nominales o fórmulas semánticas, sino que dentro de la Ley de Transparencia en comento, se han implementado los mecanismos e instrumentos tendientes a garantizar la observancia y aplicación de los preceptos en ella contenidos. En primera instancia, es de especial relevancia destacar que con esta nueva regulación el INAI tiene la facultad de resolver los recursos que se interpongan respecto de las determinaciones que señalen la reserva, confidencialidad, inexistencia o negativa de la información, teniendo estás resoluciones carácter vinculatorio además de ser inatacables. Asimismo, se ha creado el Sistema Nacional de Transparencia, Acceso a la Información Pública y Protección de Datos Personales, con el cual se pretende contribuir a la vigilancia en el cumplimiento de las obligaciones en materia de transparencia a nivel nacional, son parte integrante del sistema tanto el organismo constitucional autónomo en comento, como la Auditoría Superior de la Federación, el Archivo General de la Nación y el Instituto Nacional de Estadística y Geografía, denominados en su conjunto como Organismos Garantes.

De igual forma, se ha puntualizado que ante el incumplimiento en materia de transparencia y acceso a la información en que incurran los Partidos Políticos, se dará vista al INE o a los organismos locales, para que éstos a su vez resuelvan lo conducente.

Una vez descrito lo anterior, es importante señalar que "Una verdadera reforma política no es un acto, así sea éste de la mayor relevancia legislativa; son muchos actos, y no es un momento, sino un proceso que exige, por igual, reformas jurídicas y modificaciones que culminen en una vida mejor., 32 .

\footnotetext{
${ }^{32}$ Enciclopedia Jurídico Electoral, Op. Cit. P. 397.
} 
Observándose en el Proceso Electoral Federal y en los Procesos Electorales de las Entidades de la República del año 2015, que todavía falta mucho para que las autoridades electorales, sobretodo el INE logren superar todos los obstáculos que impiden realizar un correcto monitoreo de los Partidos Políticos en cuanto a la fiscalización se refiere.

Asimismo, el endurecimiento de las penas y sanciones en los Procedimientos Administrativos Sancionadores, es un tema de vital importancia que tendrá que ser estudiado y analizado con detenimiento no sólo por los legisladores, si no por los juristas que son los verdaderos aplicadores de la Ley, si en verdad se quiere sujetar a derecho a los Partidos Políticos, puesto que de los procesos electorales en comento se observó que, en algunos casos, a los institutos políticos les resultó particularmente intrascendente, violentar la normatividad electoral con la finalidad de lograr un mejor posicionamiento ante la ciudadanía, si recibirían como consecuencia una simple sanción económica, puesto que la ventaja que le otorgaba la violación a la normatividad era superior que el perjuicio que le ocasionaría la sanción. Situación que impide que nuestro país avance al Estado Constitucional Democrático de Derecho, puesto que aún falta mucho en el tema de las sanciones y multas en el Derecho Electoral, para lograr sujetar al derecho a los poderes fácticos, como lo son los Partidos Políticos.

Pero, estaríamos equivocados si solamente nos enfocáramos en el tema de las multas y sanciones para sujetar a derecho a los Partidos Políticos, lo más importante y lo que ayudaría con mayor fuerza al Estado y a los organismos constitucionales autónomos, y por ende a la democracia de nuestro país, sería el desarrollo de la conciencia ciudadana, entendida como una ciudadanía informada, para que sea ésta quien observe, conozca y castigue a los Partidos Políticos que transgreden la Ley con la mayor pena que existe para los mismos, como lo es el castigo en las urnas.

Puesto que sin duda alguna, el mayor paso para alcanzar el Estado Constitucional Democrático de Derecho, no lo es el desarrollo de mejores legisladores y por lo tanto de una mejor técnica legislativa; tampoco lo es el desarrollo de mejores juristas que apliquen las leyes ya no de manera legalista sino garantista en apego a los derechos humanos y fundamentales de los ciudadanos, los cuales sin duda alguna son pasos gigantescos, pero no el mayor de todos ellos; puesto que este último lo es el desarrollo de una ciudadanía informada y partícipe en la vida democrática del país.

En ese sentido, con las reformas en materia de transparencia y fiscalización, el Estado Mexicano le está otorgando todas las herramientas a sus ciudadanos para que sean una ciudadanía informada, con conocimiento del ámbito político, de las estructuras internas de todos los entes electorales, sin embargo falta lo más importante, lo que el Estado no puede otorgar o legislar, el ánimo de la ciudadanía de ser entes activos y partícipes de los procesos electorales, de tal forma que se conviertan en un verdadero legitimador de la normatividad electoral, siendo ellos una fuerza que sujete a los Partidos Políticos al derecho, pero ¿cómo lograrían hacer lo anterior?, simplemente con la sanción en las urnas, castigando a los Partidos Políticos que se caracterizaron por vulnerar las reglas del proceso electoral y a los demás entes políticos que incurrieron en innumerables violaciones a la legislación electoral con el afán inmediato de obtener una ventaja indebida y por lo tanto con el fin mediato de obtener el triunfo en las urnas.

\section{ANÁLISIS DE LA TRANSPARENCIA EN EL DERECHO COMPARADO}




\section{Argentina}

El artículo 38 de la Constitución Nacional Argentina establece que "Los Partidos Políticos deberán dar publicidad del origen y destino de sus fondos y patrimonio." Asimismo, en el año de 2009 fue promulgada parcialmente la "Ley de Democratización de la Representación Política, la Transparencia y la Equidad Electoral (Ley 26571)", la cual vino a realizar modificaciones sustanciales en materia de transparencia al Código Electoral (19.945) así como a la "Ley Orgánica de los Partidos Políticos (Ley 23.298)" y a la "Ley de Financiamiento de los Partidos Políticos (Ley 26.215)". Ésta última en específico regula en sus artículos 22 y 23 lo relacionado con informes anuales de ejercicio, estableciendo que:

Artículo 23. Estados Contables Anuales. Dentro de los noventa días de finalizado cada ejercicio, los Partidos Políticos deberán presentar ante la justicia federal con competencia electoral... el estado anual de su patrimonio o balance general y la cuenta de ingresos y egresos del ejercicio...

Deberán poner a disposición de la justicia federal con competencia electoral la correspondiente documentación respaldatoria.

Asimismo deberán presentar una lista completa de las personas físicas y jurídicas que hayan realizado aportes económicos en el período, detallando datos de identificación personal, identificación tributaria, monto y fecha del aporte.

De igual manera en el artículo 58 de la referida Ley, que a su vez fue modificado por el artículo 64 de la Ley 26571, se prevé lo concerniente a los informes que deben ser presentados por los Partidos Políticos luego de cada elección, dándole la connotación de informe final, el cual deberá presentarse ante la justicia federal electoral dentro de los noventa días siguientes después de haber finalizado la elección, en este informe se deberá detallar las aportaciones recibidas, ya sean públicas o privadas, desglosar el total del monto erogado con motivo del campaña especificando los rubros a lo que fueron destinados los recursos, lo cual deberá estar sustentado en la documentación comprobatoria correspondiente.

Así pues, la Ley 26215 en su artículo 67 (posteriormente modificado por el artículo 68 de la Ley 26571), sanciona el incumplimiento de las disposiciones referidas con antelación, es decir, para el caso en el que los Partidos Políticos no presenten en tiempo y forma los informes referentes al ejercicio anual y el consecuente después de cada elección, éstos serán multados por cada día de demora con el equivalente al $0.2 \%$ del total de fondos públicos que les hubieren correspondido y en su caso se les podrán suspender de manera cautelar todas las aportaciones públicas que pudiesen recibir.

\section{Colombia}

En la República de Colombia, la naturaleza jurídica del financiamiento estatal a los Partidos Políticos así como la publicidad en la rendición de cuentas se encuentra en el artículo 109 de su Constitución Política, el cual establece que "El Estado concurrirá a la financiación de los partidos y movimientos políticos con personería jurídica... Los partidos, movimientos y candidatos deberán rendir públicamente cuentas sobre el volumen, origen y destino de sus ingresos." 
Asimismo, en la Ley de Transparencia y del Derecho de Acceso a la Información Pública Nacional (Ley 1712) publicada el 6 de marzo de 2014, en su artículo $5^{\circ}$ se señala a los partidos o movimientos políticos como sujetos obligados dentro del ámbito de aplicación de dicha Ley, lo cual significa que los partidos deberán rendir informes respecto del ejercicio de recursos, su funcionamiento y organización, dichos informes serán de naturaleza pública y la información derivada de ellos no podrá ser reservada o limitada, lo anterior de conformidad con los principios de máxima publicidad para titular universal, transparencia, buena fe, entre otros señalados en el citado ordenamiento.

Así pues, en la Ley 130 por la que se dicta el Estatuto Básico de los partidos y movimientos políticos, dentro del Título V sobre la "Publicidad y Rendición de Cuentas", se señala en el numeral 18 que los mismos deberán presentar ante el consejo Nacional Electoral informes públicos anuales respecto de sus ingresos y egresos, del ejercicio de los recursos púbicos que les fueron asignados, así como de las erogaciones realizadas con motivo de campañas electorales, esto último dentro del mes siguiente a la conclusión del debate electoral.

Para el caso concreto de la elección del representante del ejecutivo federal, existe una regulación específica contenida en la Ley 996 por medio de la cual se reglamenta la elección de Presidente de la República, de conformidad con el artículo 152 literal f) de la Constitución Política de Colombia y de manera particular se indica en el arábigo 19 que se deberán presentar informes contables ante el Consejo Nacional Electoral por parte del gerente de campaña quien será el responsable de la rendición pública de los mismos, resultando obligados solidariamente el candidato presidencial, el gerente, el tesorero y el auditor de las campañas.

La omisión en el cumplimiento de las disposiciones citadas, será sancionado de conformidad con el artículo 39, inciso A, el cual faculta al Consejo Nacional Electoral para realizar investigaciones administrativas y en caso de omisiones, multar a los partidos, movimientos y candidatos por un monto que será directamente proporcional a la gravedad de la infracción.

\section{Chile}

La Constitución Política de Chile precisa en su artículo 18 que el sistema electoral será público, regulado por una ley orgánica y se garantizará la igualdad entre candidatos independientes y Partidos Políticos. Este último tema, es regulado por diversas disposiciones a partir de diversos ámbitos. En primer lugar, la "Ley Orgánica Constitucional de los Partidos Políticos" en su Título V "Del financiamiento de los Partidos Políticos" señala que los ingresos que perciban solo podrán ser de origen nacionales, ya sean públicos o privados, para lo cual deberán llevar un libro general en el que se especifiquen ingresos y egresos, un libro de inventario y uno de balance, los cuales les serán solicitados, por lo menos una vez al año, por el Director de Servicio Electoral para su inspección y revisión.

La contravención a dichas disposiciones será sancionada en los casos en que los ingresos de los partidos no sean exclusivamente de procedencia nacional, el artículo 50 de la ley citada señala que se podrán aplicar multas equivalentes a la gravedad de la infracción y en caso de reincidencia hasta con suspensión o disolución del partido e inhabilitación de los directivos para ocupar cargos en otros Partidos Políticos. Para los 
casos en los que no se lleven los registros en los libros, en el numeral 51 se ordena de igual manera la imposición de una multa y en los casos en que exista negligencia o dolo por parte del presidente del partido o del tesorero, también podrán quedar inhabilitados para el ejercicio de cargos directivos.

Existe también en Chile, la "Ley sobre Transparencia, Límite y Control del Gasto Electoral (Ley 19.884)" publicada el 5 de agosto de 2003, en la que se aborda todo lo relativo a el gasto electoral y sus límites, asimismo, describe los tipos de financiamiento que pueden recibir los partidos, es decir, privado o público y en cuanto a este último de manera particular se estipula que durante las campañas electorales el Estado financiará y reembolsará los gastos electorales en que incurran los candidatos y los partidos en determinadas proporciones. Aunado a lo anterior, cabe destacar que se implementa un sistema de trasparencia en el manejo de sus recursos, por ejemplo, a partir de la figura de los administradores electorales, quienes deberán llevar el control de la contabilidad electoral y presentarla ante el Director del Servicio Electoral, lo cual tendrá el carácter de información pública.

\section{España}

En España, la primera legislación relativa a la financiación del partido político como sujeto contable particular nace el 2 de julio del año 1987, con la aprobación por el Parlamento Español de la Ley Orgánica 3/1987, sobre Financiación de los Partidos Políticos, en la actualidad derogada, y que estuvo en vigor hasta el 6 de julio de 2007. La Ley de 1987, según aprecian Fidalgo Cerviño y Rodríguez López, no hacía referencia expresa ni contemplaba la necesidad de desarrollar e implantar un plan contable sectorial y específico obligatorio para las formaciones políticas españolas en ninguna de las diferentes disposiciones normativas contenidas en la misma. ${ }^{33}$ No obstante, la citada Ley de 1987 contemplaba ya, en aquel entonces, la necesidad de que las organizaciones políticas partidistas deban llevar libros de registros contables con toda precisión y detalle, de tal manera que se pueda conocer su situación económicofinanciera en cualquier momento.

Posteriormente, de acuerdo con el artículo 14 de la Ley Orgánica 8/2007, de 4 de julio, sobre Financiación de los Partidos Políticos, que vino a derogar la de 1987, los partidos políticos deben «llevar libros de contabilidad detallados que permitan en todo momento conocer su situación financiera y patrimonial y el cumplimiento de las obligaciones previstas en la presente Ley», dichos libros contables deberán contener: ${ }^{34}$

1. El inventario anual de todos los bienes. 2. La cuenta de ingresos, consignándose como mínimo las siguientes categorías de ingresos: - Cuantía global de las cuotas y aportaciones de sus afiliados. - Ingresos procedentes de su propio patrimonio. Ingresos procedentes de las donaciones a que se refieren el artículo cuatro de la citada Ley. - Subvenciones públicas. - Rendimientos procedentes de las actividades del partido. 3. La cuenta de gastos, consignándose, como mínimo, las siguientes categorías de gastos: - Gastos de Personal. - Gastos de adquisición de bienes y servicios (corrientes). - Gastos financieros de préstamos. - Otros gastos de administración. Gastos de las actividades propias del partido. 4. Las operaciones de capital relativas a: -

\footnotetext{
${ }^{33}$ Rodríguez López Ángel y Fidalgo Cerviño Esther, "Transparencia y credibilidad: el caso de los partidos políticos en España”, Partida Doble, núm. 218, págs. 18-24.

${ }^{34}$ Ídem.
} 
Créditos o préstamos de instituciones financieras. - Inversiones. - Deudores y acreedores

En la actualidad, y como consecuencia de la aprobación de la Ley Orgánica 5/2012, de 22 de octubre, de reforma de la Ley Orgánica 8/2007, se ha adicionado un apartado ocho al artículo 14 de la citada ley, que queda redactado en los siguientes términos: «Ocho. Los partidos políticos, una vez emitido por el Tribunal de Cuentas el informe de fiscalización correspondiente a un determinado ejercicio, vendrán obligados a hacer públicas, preferentemente a través de su página web, el balance y la cuenta de resultados y, en particular, la cuantía de los créditos que les han sido concedidos, el tipo de entidad concedente y las condonaciones de deuda correspondientes a tal ejercicio, de forma que esta información sea de gratuito y fácil acceso para los ciudadanos.»

También, en aras de una mayor transparencia, en la ley 5/2012 se modifica el artículo 15 de la Ley Orgánica 8/2007 y se establece que: «Los partidos políticos deberán prever un sistema de control interno que garantice la adecuada intervención y contabilización de todos los actos y documentos de los que se deriven derechos y obligaciones de contenido económico, conforme a sus estatutos. El informe resultante de esta auditoría acompañará a la documentación a rendir al Tribunal de Cuentas.»

En cuanto al carácter de los partidos políticos españoles como sujetos pasivos de las disposiciones de transparencia, el artículo 3 de la Ley de Transparencia, Acceso a la Información Pública y Buen Gobierno, la cual data de 9 de diciembre de 2013, establece: «Las disposiciones del capítulo II de este título serán también aplicables a: a) Los partidos políticos, organizaciones sindicales y organizaciones empresariales. b) Las entidades privadas que perciban durante el período de un año ayudas o subvenciones públicas en una cuantía superior a 100.000 euros o cuando al menos el $40 \%$ del total de sus ingresos anuales tengan carácter de ayuda o subvención pública, siempre que alcancen como mínimo la cantidad de 5.000 euros»

Por otra parte, Villoria considera importante señalar también que los partidos políticos tienen la posibilidad de obtener ingresos por la vía de sus fundaciones y empresas ${ }^{35}$, y es en ese sentido que, con respecto a las primeras se ha desarrollado, a partir de la citada Ley 5/2012, un mayor control y transparencia, así, por la Ley 5/2012 se modifica la disposición adicional séptima de la Ley Orgánica 8/2007, de 4 de julio, sobre Financiación de los Partidos Políticos, que queda redactada en los siguientes términos: «Disposición adicional séptima. Uno. Las aportaciones que reciban las fundaciones y asociaciones vinculadas a los partidos políticos con representación parlamentaria estarán sometidas a los mecanismos de fiscalización y control y al régimen sancionador, previstos, respectivamente, en los títulos V y VI de esta Ley, sin perjuicio de las normas propias que les sean de aplicación [...]. Cinco. Las fundaciones y asociaciones reguladas en esta disposición adicional estarán obligadas a formular y aprobar sus cuentas en los términos previstos en la legislación vigente y a realizar una auditoría de sus cuentas anuales. Una vez emitido por el Tribunal de Cuentas el informe de fiscalización de las aportaciones a las que se refiere el apartado Uno de este artículo, vendrán obligadas a hacer públicas, preferentemente a través de su página web, el balance y la cuenta de resultados de forma que esta información sea de gratuito y fácil acceso para los ciudadanos. [...]. Seis. Las fundaciones y asociaciones reguladas por esta disposición adicional estarán obligadas a informar anualmente al Ministerio de

\footnotetext{
${ }^{35}$ Villoria, Manuel, La publicidad activa en la Ley de Transparencia, Acceso a la Información y Buen Gobierno: posibilidades e insuficiencias, Universidad Rey Juan Carlos, 2014, Págs. 45-46.
} 
Hacienda y Administraciones Públicas de todas las donaciones y aportaciones recibidas, a cuyo fin se aprobará una orden ministerial en la que se indicarán el contenido, alcance y estructura de la información que ha de facilitarse. Además, todas las donaciones procedentes de personas jurídicas deberán ser objeto de notificación al Tribunal de Cuentas en el plazo de tres meses.»

\section{Comparación}

Como se puede observar en los párrafos que anteceden, la obligación de transparentar el actuar de los Partidos Políticos, es una obligación que el Estado Mexicano se encontraba obligado a legislar e implementar, lo anterior en virtud de que algunos países de Iberoamérica como Chile, Argentina, Colombia y España, ya habían legislado e implementado mecanismos para transparentar los recursos que recibían los Partidos Políticos.

Así las cosas, el Estado Mexicano fue más allá de lo que contemplaban las legislaciones de los países señalados, puesto que las referidas legislaciones se dedicaban y hacían especial énfasis en las cuestiones fiscales de los partidos políticos, esto es en los recursos que percibían dichos institutos políticos y el destino que se les daban a los mismos. Sin embargo, las reformas realizadas por México específicamente en la materia de transparencia, establecieron nuevas disposiciones normativas que fueron más allá de la simple fiscalización y transparencia de los recursos de los institutos políticos, puesto que con la reforma en materia de transparencia se creó una nueva ley de transparencia, la Ley General de Transparencia y Acceso a la Información Pública, la cual entre otras cosas regula y considera a los partidos políticos como sujetos obligados en materia de transparencia, por lo que se les impuso la obligación de tener a disposición de toda la ciudadanía en sus páginas oficiales de internet la información considerada por la ley como pública de oficio ${ }^{36}$ y adicional a dicha información se estableció una disposición normativa que específicamente señala qué tipo de información deben de tener a disposición de la ciudadanía los partidos políticos ${ }^{37}$; catálogo de información que a diferencia de Chile, Argentina, Colombia y España, es mucho más amplio y abarca más aspectos de los institutos políticos.

En esa línea argumentativa, México a diferencia de Chile, Argentina, Colombia y España, en la reforma en materia de transparencia, específicamente en la multireferida Ley General de Transparencia, obligó a los partidos políticos a contar con dos organismos internos que permitirían implementar la señalada reforma, así como dar operatividad a la reforma en materia política-electoral en cuestiones de transparencia, dichos organismos son las Unidades de Transparencia ${ }^{38}$ y los Comités de Transparencia $^{39}$ y no sólo eso, si no que estableció la implementación de un sistema y una plataforma nacional para garantizar a los ciudadanos el acceso a la información de dichos institutos políticos y demás sujetos obligados por dicha ley, figuras a las cuales

\footnotetext{
${ }^{36}$ Artículo 70 de la Ley General de Transparencia y Acceso a la Información Pública.

${ }^{37}$ El artículo 76 de la Ley en comento, señala que, entre otros, debe contar con el padrón de afiliados o militantes, los acuerdos y resoluciones de los órganos de dirección de los partidos políticos, los convenios de participación entre partidos políticos con organizaciones de la sociedad civil y los contratos y convenios para la adquisición o arrendamiento de bienes y servicios, por mencionar algunos.

${ }^{38}$ Ibídem, artículo 45.

${ }^{39}$ Ibídem, artículos 43 y 44.
} 
se les denominó en la ley como el Sistema Nacional de Transparencia ${ }^{40}$ y la Plataforma Nacional del Transparencia ${ }^{41}$.

Así las cosas, a diferencia de los países con los que se compara la legislación mexicana en materia de transparencia y fiscalización de los Partidos Políticos, México ha llevado a cabo reformas de gran envergadura que han logrado superar en contenido a las de otros países, estableciendo no solo modificaciones al interior de los institutos políticos, sino dotando de nuevas herramientas a las autoridades y a los ciudadanos para poder acceder a la información generada por los Partidos Políticos, y estableciendo sistemas y herramientas a nivel nacional con la finalidad de que los ciudadanos tengan acceso de manera permanente a la información generada por los institutos políticos en comento.

Por dar algunos ejemplos, en Chile la Ley de Transparencia de la Función Pública y de Acceso a la Información de la Administración del Estado, no contempla como sujetos obligados de dicha ley a los Partidos Políticos; sin embargo dicho país cuenta con una disposición específica que regula solamente el gasto realizado por los Partidos Políticos en las elecciones, en la Ley del Gasto electoral. Por tanto, se advierte con meridiana claridad que dicho país, a diferencia de México, se ha concentrado únicamente en la transparencia de los Partidos Políticos con relación a los recursos que percibe para las elecciones y para qué fines los destina, dejando por un lado otros temas de suma importancia, como transparentar su estructura orgánica, los procesos jurisdiccionales internos, los procesos de elección de candidatos, entre otras cuestiones.

En Argentina, a la fecha de presentación de este trabajo, aún no contaba con una Ley Nacional de Acceso a la Información Pública, por lo tanto, a diferencia de México, no posee una legislación, ni con un organismo especializado que regule cuestiones de transparencia en todo el país, y mucho menos de los partidos políticos. ${ }^{42}$

Las disposiciones normativas en materia de Transparencia en partidos políticos de España son similares a las de México, la Ley 19/2013, de 9 de diciembre, de transparencia, acceso a la información pública y buen gobierno, contempla como sujetos obligados de la misma a los Partidos Políticos, establece un catálogo de información que debe de ser considerada pública y estar a disposición de la ciudadanía en los portales de internet de los sujetos obligados; sin embargo a diferencia del Estado mexicano, sus disposiciones van encaminadas a regular e implementar la cultura de la transparencia en los Órganos del Estado, por lo que no regula de manera específica cuestiones de transparencia de los Partidos Políticos de suma importancia.

En lo que respecta a Colombia, la Ley de Transparencia y del Derecho de Acceso a la Información Pública Nacional al igual que en el caso de España, establece disposiciones que van encaminadas a la transparencia en general de los Organismos del Estado, y no contempla disposiciones específicas en materia de transparencia que deben cumplir los Partidos Políticos; asimismo a diferencia de la legislación mexicana no obliga a los Partidos Políticos a establecer órganos internos que serán los responsables de transparentar el actuar de dichos institutos políticos.

\footnotetext{
${ }^{40}$ Artículos 28 y 29 de la Ley General de Transparencia y Acceso a la Información Pública.

${ }^{41}$ Artículos 49, 50, 51 y 52 de la Ley General de Transparencia y Acceso a la Información Pública.

${ }^{42}$ En mayo de 2016, la Cámara Diputados de la República Argentina aprobó el proyecto de Ley de Acceso a la Información Pública, aún falta la aprobación del Senado. Véase, La Nación, Diputados aprobó la ley de Acceso a la Información Pública y resta la sanción del Senado, 18 de mayo de 2016, http://www.lanacion.com.ar/1900085-diputados-aprobo-la-ley-de-acceso-a-la-informacion-publica-yresta-la-sancion-del-senado. Fecha de acceso: 2 de agosto de 2016.
} 


\section{CONCLUSIONES}

En los estados contemporáneos basados en un sistema de partidos, dichos entes de interés público se han afianzado en la realidad social, política y económica como verdaderos poderes fácticos que han superado a los sistemas normativos y a las autoridades del Estado que los regulan y vigilan, por lo que constantemente laceran al sistema jurídico, a la democracia y por ende al Estado Democrático Constitucional de Derecho.

Por lo anterior el Estado Mexicano llevó a cabo una serie de reformas sistematizadas en las materias de transparencia, política-electoral, hacendaria y de derechos humanos que establecieron nuevas disposiciones normativas, las cuales otorgaron nuevas herramientas a los órganos constitucionales autónomos encargados de sujetar al derecho a los Partidos Políticos, esto con la finalidad de crear un sistema de pesos y contrapesos limitando el poder de los Partidos Políticos y sujetando su actuación al derecho, creando por primera vez, una reforma política-electoral que regulara la estructura interna de los Partidos Políticos y estableciera los órganos internos mínimos con los que debe contar en acatamiento de las disposiciones en materia de transparencia y fiscalización de partidos.

No pasa desapercibido el hecho de que, en otras democracias, el establecimiento de normas que regulan el acceso a la información de los Partidos Políticos así como el comportamiento de éstos, promete dar mayor certeza y seguridad a la ciudadanía, pues las mismas leyes u ordenamientos crean los supuestos normativos que deberán ser aplicados a casos de ejercicio del sufragio, previendo a su vez los mecanismos para hacerlos exigibles y la manera de sancionar su incumplimiento, lo que permite mayor información a la ciudadanía y confianza de ésta hacia las instituciones políticas.

En tal sentido, México también trabaja en la legitimación del sistema normativo estatal y federal, así como el de sus autoridades políticas, cuyo último fin, va encaminado a conformar una ciudadanía informada que obligue a los Partidos Políticos a sujetarse al derecho, motivando el alcance de toda información del ámbito político que lleve a crear conciencia y reforzar el sistema democrático en México.

\section{BIBLIOGRAFÍA}

Acuña Llamas, Javier, "Conferencia magistral Alcance de la Reforma en Materia de Transparencia: El tema de los Partidos Políticos. Comisión de Acceso a la Información Pública y Protección de Datos Personales del estado de Tlaxcala", México, 2013, http://inicio.ifai.org.mx/Comunicados/Comunicado\%20IFAI-070-14.pdf.

Anaiga Vargas, Ma. Del Carmen, Notas sobre el Estado Constitucional Democrático de Derecho, http://www.letrasjuridicas.com/Volumenes/7/ainaga7.pdf

"ANÁLISIS COMPARATIVO DE LA REFORMA ELECTORAL CONSTITUCIONAL Y LEGAL 2007-2008", México, IFE, noviembre de 2008, http://www.ife.org.mx/documentos/Reforma_Electoral/docs/AC_RefElect0708.pdf. 
Análisis del Sistema Electoral Méxicano-Informe de un Grupo de Expertos, "La Reforma Electoral de 1996: Contexto Histórico-Político", http://biblio.juridicas.unam.mx/libros/3/1116/3.pdf.

Atienza, Manuel. El Derecho como Argumentación, Instituto de Investigaciones Jurídicas de la UNAM, http://biblio.juridicas.unam.mx/libros/4/1695/4.pdf

Barquín, Manuel, "LA REFORMA ELECTORAL DE 1986-1987 EN MÉXICO RETROSPECTIVA Y ANÁLISIS", Instituto Interamericano de Derechos HumanosCAPEL, San José de Costa Rica, 1987, http://www.bibliojuridica.org/libros/2/650/6.pdf.

Cámara de Diputados del H. Congreso de la Unión, "Ley General de Partidos Políticos", Estados Unidos Mexicanos, 23 de mayo de 2014, http://www.diputados.gob.mx/LeyesBiblio/pdf/LGPP_100914.pdf.

Cámara de Diputados del H. Congreso de la Unión, "Reglamento de transparencia y acceso a la Información Pública Gubernamental", Estados Unidos Mexicanos, 14 de julio de 2014, http://www.diputados.gob.mx/LeyesBiblio/pdf/244_140714.pdf.

Chacón Rojas, Oswaldo, "Informe de labores de funcionarios públicos y la garantía de equidad en las contiendas”, Temas selectos de Derecho Electoral. México, 2013.

Chávez Becerra, Pablo Javier, "La Reforma Electoral de 1996”, México, Universidad Autónoma http://biblio.juridicas.unam.mx/libros/4/1834/8.pdf.

Metropolitana-Iztapalapa,

Constitución Nacional Argentina. Argentina, 01 de mayo de 1853.

Constitución Política de Colombia. Gaceta Constitucional, Colombia, 1991.

Constitución Política de la República de Chile. Diario Oficial, República de Chile, 24 de octubre de 1980.

Constitución Política de los Estados Unidos Mexicanos.

Constitución Política del Estado Plurinacional de Bolivia. Bolivia, 09 de diciembre de 2007.

Córdova Vianello, Lorenzo, "LA REFORMA ELECTORAL Y EL CAMBIO POLÍTICO EN MÉXICO”, México, UNAM, http://biblio.juridicas.unam.mx/libros/6/2527/17.pdf.

De la Madrid Andrade, Mario (Coord.), "Derecho Procesal. Temas diversos", México, Universidad de Colima, 2008.

Diario Oficial de la Federación, "Decreto por el que se expide la Ley Federal para la Prevención e Identificación de Recursos de Procedencia Ilícita", Estados Unidos $\begin{array}{llllll}\text { Mexicanos, } & 17 & \text { de } & \text { octubre }\end{array}$ http://www.dof.gob.mx/nota_detalle.php?codigo=5273403\&fecha=17/10/2012.

Diario Oficial de la Federación, "Decreto por el que se expide la Ley General de Instituciones y Procedimientos Electorales; y se reforman y adicionan diversas disposiciones de la Ley General del Sistema de Medios de Impugnación en Materia Electoral, de la Ley Orgánica del Poder Judicial de la Federación y de la Ley Federal de Responsabilidades Administrativas de los Servidores Públicos", Estados Unidos 
Mexicanos, 23 de mayo de 2014, http://dof.gob.mx/nota_detalle.php?codigo=5345952\&fecha=23/05/2014.

Diario Oficial de la Federación, "Decreto por el que se expide la Ley General de Partidos Políticos", Estados Unidos Mexicanos, 23 de mayo de 2014, http://dof.gob.mx/nota_detalle.php?codigo=5345955\&fecha=23/05/2014.

Diario Oficial de la Federación, "Decreto por el que se expide la Ley General en Materia de Delitos Electorales", Estados Unidos Mexicanos, 23 de mayo de 2014, http://dof.gob.mx/nota_detalle.php?codigo=5345956\&fecha=23/05/2014.

Diario Oficial de la Federación, "Decreto por el que se expide la Ley General de Transparencia y Acceso a la Información Pública", Estados Unidos Mexicanos, 04 de mayo de 2015 , http://www.dof.gob.mx/nota_detalle.php?codigo=5391143\&fecha=04/05/2015.

Diario Oficial de la Federación, "Decreto por el que se modifica la denominación del Capítulo I del Título Primero y reforma diversos artículos de la Constitución Política de los Estados Unidos Mexicanos" 10 de junio de 2011, http://dof.gob.mx/nota_detalle.php?codigo=5194486\&fecha=10/06/2011.

Diario Oficial de la Federación, "Decreto por el que se reforman, adicionan y derogan diversas disposiciones de la Constitución Política de los Estados Unidos Mexicanos, en materia política-electoral", 10 de febrero de 2014, http://dof.gob.mx/nota_detalle.php?codigo=5332025\&fecha=10/02/2014.

Diario Oficial de la Federación, "Decreto por el que se reforman y adicionan diversas disposiciones de la Constitución Política de los Estados Unidos Mexicanos, en materia de Transparencia”, 07 de febrero de 2014, http://dof.gob.mx/nota_detalle.php?codigo=5332003\&fecha=07/02/2014.

Diario Oficial de la Federación, "DECRETO que reforma y adiciona los artículos 6o., 41, 51, 52, 53, 54, 55, 60, 61, 65, 70, 73, 74, 76, 93, 97 y 115 de la Constitución Política de los Estados Unidos Mexicanos", Estados Unidos Mexicanos, 06 de diciembre de 1977, http://www.dof.gob.mx/nota_detalle.php?codigo=4664439\&fecha=06/12/1977.

Diario Oficial de la Federación, "Reglamento de la Ley Federal para Prevención e Identificación de Operaciones con Recursos de Procedencia Ilícita", Estados Unidos Mexicanos, 16 de agosto de 2013, http://www.dof.gob.mx/nota_detalle.php?codigo=5310763\&fecha=16/08/2013.

Diario Oficial de la Federación, "Decreto por el que se declaran reformadas y derogadas diversas disposiciones de la Constitución Política de los Estados Unidos Mexicanos, en materia de la reforma política de la Ciudad de México", 29 de enero de 2016, http://dof.gob.mx/nota_detalle.php?codigo=5424043\&fecha=29/01/2016. Fecha de acceso: 9 de junio de 2016.

Enciclopedia Jurídico Electoral de México. Normas Rectoras Jurídico Electorales. t. I. México Líder Nacional.

Häberle, Peter, El Estado Constitucional, "Concepto, fundamentación del objeto y métodos de trabajo", 1ra reimpresión, México, UNAM, 2003, http://biblio.juridicas.unam.mx/libros/libro.htm? $l=14$. 
Instituto Nacional Electoral, "Programa de Acompañamiento Ciudadano 2014” México, http://pac.ife.org.mx/para_saber_mas_reformas_estructurales.html.

Jiménez Díaz Antonio y Morán Torres Enoc Francisco, "Los pactos entre líderes de fuerzas políticas, experiencias iberoamericanas. El desafío de la democracia participativa en la construcción de un proyecto de Estado Constitucional y Democrático de Derecho" en Vidaurri Aréchiga Manuel et al., (coords.) Conciencia jurídica Mexicana, México, Porrúa, 2014.

La Nación, Diputados aprobó la ley de Acceso a la Información Pública y resta la sanción del Senado, 18 de mayo de 2016, http://www.lanacion.com.ar/1900085diputados-aprobo-la-ley-de-acceso-a-la-informacion-publica-y-resta-la-sancion-delsenado.

Ley 130. Estatuto Básico de los partidos y movimientos políticos. Diario Oficial, Colombia, 23 de marzo de 1994.

Ley 17.799. Declaración Jurada de los Candidatos de los Partidos Políticos. Diario Oficial, República Oriental del Uruguay, 19 de agosto de 2004.

Ley 1712. Ley de Transparencia y del Derecho de Acceso a la Información Pública Nacional. Diario Oficial, Colombia, 06 de marzo de 2014.

Ley 18603. Ley Orgánica Constitucional de los Partidos Políticos. República de Chile, 23 de marzo de 1987.

Ley 19.884. Ley sobre Transparencia, Límite y Control del Gasto Electoral. República de Chile, 05 de agosto de 2003.

Ley 23.298. Ley Orgánica de los Partidos Políticos. Boletín Oficial de la República Argentina, Argentina, 22 de octubre de 1985.

Ley 26.215. Ley de Financiamiento de los Partidos Políticos. Boletín Oficial de la República Argentina, Argentina, 15 de enero de 2007.

Ley 26571. Ley de Democratización de la Representación Política, la Transparencia y la Equidad Electoral. Boletín Oficial de la República Argentina, Argentina, 02 de diciembre de 2009.

Ley 996. Reglamenta la elección de Presidente de la República, de conformidad con el artículo 152 literal f) de la Constitución Política de Colombia. Diario Oficial, Colombia, 24 de noviembre de 2005

Nájera Meixieiro, Gustavo y Moreno Pliego, Iván H, "Reformas electorales en México: evolución y pendientes", Centro de Estudios Sociales y de Opinión Pública, México, núm. 91, mayo 2010, file:///C:/Users/marco/Downloads/Docto_91_Reformas_electorales_Mexico_2010\%20( 2).pdf.

"Reformas electorales en México", Centro de Capacitación Judicial Electoral, 2012, http://www.ieemorelos.org.mx/site/documents/9e/camt/5presentacion.pdf.

Rendón Gil, Raymundo. El Estado Constitucional de Derecho y los Derechos Humanos, http://www.tfjfa.gob.mx/investigaciones/pdf/estadoconstitucionaldederechoylosderecho shumanos.pdf 
Rodríguez Hernández, Edmundo Carlos, "La reforma constitucional electoral 2007 en México", México, UNAM, http://www.juridicas.unam.mx/publica/librev/rev/sufragio/cont/1/ens/ens11.pdf.

Ruiz Rodríguez, Virgilio. Estado de Derecho y Soberanía, http://www.juridicas.unam.mx/publica/librev/rev/jurid/cont/34/pr/pr16.pdf

Sampedro, José Luis y otros. Reacciona, https://nomesesunblog.files.wordpress.com/2011/05/54771304-reacciona.pdf

Valdés Zurita, Leonardo, "El estado de cambio político en México: De la transición a la consolidación de la Democracia", Conferencia dictada en el marco del IV Congreso Internacional y XXII Nacional de Estudios Electorales de la Sociedad Mexicana de Estudios Electorales, 2 de septiembre de 2011, http://www.ine.mx/docs/IFEv2/CNCS/CNCS-VersionesEstenograficas/2011/Septiembre/020911.pdf. 